\title{
DOCUMENTOS OFICIAIS DE EDUCAÇÃO NO BRASIL E A TEORIA CONSTRUTIVISTA PIAGETIANA
}

\author{
DOCUMENTOS OFICIALES DE EDUCACIÓN EN BRASIL Y LA TEORÍA \\ CONSTRUTIVISTA PIAGETIANA
}

\section{OFFICIAL DOCUMENTS OF EDUCATION IN BRAZIL AND THE PIAGETIAN CONSTRUTIVISM THEORY}

Maria Aparecida Rosa de ANDRADE ${ }^{1}$ Maria Das Graças de Almeida BAPTISTA ${ }^{2}$

RESUMO: O presente artigo teve como problemática investigar a origem da teoria construtivista e analisar os Documentos Oficiais de Educação. Tal estudo justifica pelo pressuposto que diferentes associações feitas pelos professores em relação à teoria e a prática encontram-se dialeticamente relacionadas às propostas oficiais de educação. A metodologia desse estudo desenvolve-se em uma perspectiva marxista e tem como referencial teórico a práxis, em Gramsci e Vásquez, entendida como a ação consciente dos sujeitos que une a teoria à prática, levando à transformação do mundo e dos próprios sujeitos. Esse caminho inclui o destaque das contradições presentes nos documentos e nos depoimentos de docentes e discentes Nesse sentido, espera-se que este estudo possa servir de parâmetro para aqueles que desejam conhecer e refletir a realidade educacional em uma perspectiva construtivista, pois a escola é um conjunto, um todo, e não pode ser vista de modo fragmentado.

PALAVRAS-CHAVE: Educação. Teoria. Documentos oficiais de educação.

RESUMEN: El presente artículo tuvo como problemática investigar el origen de la teoría constructivista y analizar los Documentos Oficiales de Educación. Este estudio justifica por el supuesto de que diferentes asociaciones hechas por los profesores en relación a la teoría y la práctica se encuentran dialécticamente relacionadas con las propuestas oficiales de educación. La metodología de este estudio se desarrolla en una perspectiva marxista y tiene como referencial teórico a la praxis, en Gramsci y Vásquez, entendida como la acción consciente de los sujetos que une la teoría a la práctica, llevando a la transformación del mundo y de los propios sujetos. Este camino incluye el destaque de las contradicciones presentes en los documentos y en los testimonios de docentes y discentes En ese sentido, se espera que este estudio pueda servir de parámetro para aquellos que desean conocer y reflejar la realidad educativa desde una perspectiva constructivista, pues la escuela es un "conjunto, un todo, y no puede ser vista de modo fragmentado.

${ }^{1}$ Universidade Federal da Paraíba (UFPB), João Pessoa - PB - Brasil. Pesquisadora do Grupo de ÁGORA/UFPB. ORCID: 〈http://orcid.org/0000-0002-5352-070X〉. E-mail: andrade_alcantara2011@live.com

${ }^{2}$ Universidade Federal da Paraíba (UFPB), João Pessoa - PB - Brasil. Professora vinculada ao Departamento de Fundamentação da Educação. Líder do Grupo de Estudos e Pesquisa em Filosofia e Psicologia da Educação ÁGORA/UFPB. ORCID: <http://orcid.org/0000-0003-1084-4269>. E-mail: andrade_alcantara2011@live.com 
PALABRAS CLAVE: Educación. Teoría. Documentos oficiales de educación.

ABSTRACT:The present article had as problematic to investigate the origin of the constructivist theory and to analyze the Official Education Documents. Such a study justifies the assumption that different associations made by teachers in relation to theory and practice are dialectically related to official educational proposals. The methodology of this study is developed in a Marxist perspective and has as theoretical reference the praxis, in Gramsci and Vásquez, understood as the conscious action of the subjects that unites theory to practice, leading to the transformation of the world and the subjects themselves. In this sense, it is hoped that this study can serve as a parameter for those who wish to know and reflect the educational reality in a constructivist perspective, since the school is a whole, and can't be seen in a fragmented way.

KEYWORDS: Education. Theory. Official education documents.

\section{Introdução}

A educação brasileira é resultado de uma longa história, que carrega heranças coloniais pautados em interesses econômicos e políticos da época. Como efeito, chegou ao Brasil modelos, concepções e teorias de educação que não surgiu ou foi pensada a partir de nossa realidade educacional, mas sim implantada e "adaptada" a realidade.

Nessa perspectiva, depois da primeira guerra Mundial e com a expansão do capitalismo foram surgindo necessidades de mão de obra qualificada, resultando em grandes rupturas, mudanças e avanços no meio educacional. Essas mudanças ganharam força no final do século XIX e XX, tais ideias de uma nova educação chegaram ao Brasil oriundo da Europa e dos Estados Unidos, através de professores e estudiosos, trazendo as pesquisas de Jean Piaget e outros pesquisadores, que ganharam grande destaque na fundamentação do movimento da Escola Nova no Brasil (uma nova perspectiva de ensino voltado para as necessidades do país).

Contudo, a educação brasileira passou por movimentos de mudanças, foi na década de 1930, após a publicação do Manifesto dos Pioneiros da Educação Nova esse tinha como objetivo central defender o direito a escola pública, laica e gratuita. Em dezembro de 1961 foi criada a Lei de Diretrizes e Bases da Educação, sendo alterada em 1971 sendo sancionada em 1996 em vigor até os dias atuais. Trazendo uma concepção de Educação crítica, buscando a formação do sujeito em sua totalidade, nesse o papel do professor, do aluno e o objetivo da educação mudaram como veremos no desenvolver do artigo. 
Nessa vertente, a partir do ano de 1980 começou a ser divulgado no Brasil estudos da psicogenética da língua escrita da pesquisadora Emília Ferreiro, tal divulgação e expansão dessa pesquisa resultou em mudanças na educação brasileira, na maneira de pensar e planejar o processo de alfabetização. Passando o ensino de uma forma mecânica de codificação e decodificação, para ser compreendido como um processo de construção que apresenta diferentes etapas. Os estudos de Emília Ferreiro trazem influências e concepções da Teoria do conhecimento de Jean Piaget que, por sua fez, foi seu orientador de doutorado e com o qual por muitos anos Emília Ferreiro foi sua colaboradora.

Vamos agora conhecer um pouco mais do pesquisador Jean Piaget que em seus estudos derrubou a concepção de um universo de conhecimento pronto e acabado. A grande questão da epistemologia genética desse estudioso era entender "Qual a origem do conhecimento?" A partir dessa pergunta surgiu uma pluralidade de questionamentos a respeito da estrutura do conhecimento, originando a sua "Teoria do Conhecimento" que, ao longo de seus estudos, denominou "Teoria Construtivista" sendo essa, uma teoria de adaptação do pensamento a realidade.

Piaget defendia a ideia de um conhecimento construído e contextualizado, sendo os pensamentos individuais responsáveis por formar a consciência crítica e particular de cada ser, em uma interação do sujeito com o "objeto" desconhecido, passando por um processo dialético de descobertas e construções, o que era antes desconhecido, agora é reconhecido e assimilado pelo sujeito.

Nessa vertente, o objetivo da educação intelectual mudou. Como destaca Jean Piaget (1975), o verdadeiro objetivo não é saber repetir ou conservar verdades acabadas, pois uma verdade que é reproduzida não passa de uma semiverdade. É nesse contexto que a teoria construtivista se apresenta com o propósito de ir além do alcance das mudanças sociais, para o atendimento de novas demandas. Para que esse objetivo seja alcançado, a escola não deve apenas, acompanhar o processo de pleno desenvolvimento social e econômico, mas a partir deste, construir o conhecimento junto com os alunos, de forma crítica e reflexiva.

No Livro a Psicologia e Epistemologia: por uma Teoria do Conhecimento, Piaget (1978, p.30) ressalta que "a teoria do conhecimento é, sem dúvida, essencialmente, uma teoria da adaptação do pensamento á realidade, mesmo se essa adaptação revela, no final das contas, como, aliás, todas as adaptações, a existência de uma inextricável interação entre sujeito e objeto". 
No campo educacional, para que essa interação se efetive, deve haver uma comunicação significativa e contextualizada entre docente e discente, numa constante troca de conhecimentos e saberes cotidianos que são geradores de novos conhecimentos, não sendo essa uma tarefa fácil. Como aponta Piaget, em seu livro Psicologia e Pedagogia (1972, p. 75), “exigem do mestre um trabalho bem mais diferenciado e bem mais ativo, enquanto dar lições é menos fatigante e corresponde a uma tendência muito mais natural no adulto em geral e no adulto pedagogo em particular.”.

Nessa perspectiva, busca-se com esse texto analisar a difusão da Teoria Construtivista na educação brasileira, assim como identificar possíveis elementos da teoria nos atuais documentos oficiais de educação. Contudo, espera-se que este estudo possa servir para aqueles que desejam conhecer e refletir sobre a influência da teoria construtivista na realidade educacional brasileira.

\section{Teoria construtivista na educação brasileira}

A Teoria Construtivista tem suas bases nos estudos de Jean Piaget. Esse pesquisador não tinha como objetivo criar uma teoria ou um método para educação, mas buscava responder a uma pergunta "Como o homem constrói conhecimento?". Ao longo de sua pesquisa, destacou os processos e etapas de construção da consciência e inteligência, estudou o modo como aprendemos e como conseguimos passar de um nível de conhecimento para outro, uma vez que, a inteligência divide-se em função e estrutura, em adaptação (modificação do meio) e na organização de processo, para reorganizar a inteligência.

Nessa vertente, o sujeito aprende mais quando interage com o objeto estudado, tendo subsídios parar construir seu próprio conhecimento, partindo de conhecimentos que já possui e de sua vivência social e cultural. Assim, o construtivismo é uma teoria que busca tornar o homem um ser criativo, pensante, no processo de seu desenvolvimento, o que ocorre devido à interação com o meio físico e social e aos estímulos que são oferecidos ao sujeito. Desse modo, a teoria construtivista veio para revolucionar a educação, saindo de um processo mecânico para uma visão crítica de construção de conhecimento.

Entretanto, mudar a orientação da educação não depende do professor. De acordo com Rosa (2007, p. 25-26), a “educação não se realiza sobre coisas ou a partir delas. Não há educação sem alguém que a anime. E não há educador que não se revele e que não se coloque por inteiro em suas ações. Educar é um ato de intenção, em que ser humano e profissional se 
fundem.”. No entanto, os sujeitos passam por diferentes estágios evolutivos em ritmos diferentes, sendo que as características cognitivas são formadas a partir da constante interação do sujeito com o meio físico e social, e as dimensões interpessoais e cultura.

Para explicar este desenvolvimento cognitivo, Azenha (1999, p. 23-24) destaca que "esse modo de funcionamento intelectual é permanente e continuo durante toda a vida humana, apresentando algumas características e propriedades. Esta permanência e continuidade fazem dessas características verdadeiras "invariantes funcionais"”. O aluno é um ser ativo, que concebe prepara e executar o próprio trabalho e o professor sugere ideias, auxilia quando necessário e coordena o processo, ampliando a estrutura lógica dos discentes.

A Teoria Construtivista tem ganhado espaço e vem mudando a concepção e a prática de educadores. Apesar de Jean Piaget ser o "pai" desta teoria, quem a fez chegar ao Brasil foi, em parte, sua discípula Emilia Ferreiro. No ano de 1980, essa teoria chegou de forma expansiva ao Brasil, abordada principalmente em eventos de educação.

É importante destacar quem era Emília Ferreiro. Ferreiro nasceu na Argentina no ano de 1936, fez doutorado na Universidade de Genebra, sob a orientação de Jean Piaget. A pesquisa de Ferreiro destacava os mecanismos cognitivos da leitura e da escrita, sendo esse um aspecto que seu orientador não tinha explorando nos seus estudos.

Uma das primeiras obras da autora que teve uma edição brasileira foi "Psicogênese da Língua escrita", no ano de 1984. A partir dessa obra, os estudos de Emília Ferreiro e a teoria construtivista de Piaget passaram a influenciar e orientar o campo educacional no Brasil.Os estudos de Ferreiro, assim como os de Piaget, levaram a conclusão que o sujeito deve ser ativo no processo de aprendizagem e passaram a estar ligados ao construtivismo de Piaget. Essa influencia provocou uma reforma no ensino, alterando os papéis dentro da sala de aula, não sendo mais o professor o único detentor do saber, o conhecimento prévio do aluno passa a ser valioso para o processo de aprendizagem e a ser observado o desenvolvimento cognitivo do aluno, para isso faz-se necessário um ambiente estimulador, que provoque, levando o aluno à construção de conhecimento.

No artigo "O que é Construtivismo", Becker (2001, p. 72) sinaliza que o construtivismo, em Piaget, é "uma teoria, um modo de ser do conhecimento ou um movimento do pensamento que emerge do avanço das ciências e da Filosofia dos últimos séculos. Uma teoria que nos permite interpretar o mundo em que vivemos". Ou seja, "não é uma prática ou um método; não é uma técnica de ensino nem uma forma de aprendizagem; não é um projeto escolar; é, sim, uma teoria que permite (re)interpretar todas essas coisas, jogando-nos para dentro do 
movimento da História da humanidade e do universo". Nesse sentido, os alunos devem ser estimulados a pensar e refletir no processo de sistematização do pensamento, ou seja, o sujeito não é um ser passivo, ele age e interage no meio, transformado o meio e a si mesmo.

Para Becker (2001, p. 72) o construtivismo significa "a ideia de que nada, a rigor, está pronto, acabado, e de que, especificamente, o conhecimento não é dado, em nenhuma instância, como algo terminado-é sempre um leque de possibilidades que podem ou não ser realizadas". O conhecimento é, assim, "constituído pela interação do indivíduo com o meio físico e social, com o simbolismo humano, com o mundo das relações sociais".

Dessa forma, a teoria construtivista parte inicialmente do pressuposto da construção e reconstrução do conhecimento e que qualquer conhecimento em qualquer instância está sempre em processo de mudança e de ampliação, em processo de formação e reformulação. Nesse processo, o erro não é visto como algo negativo, mas sim como uma ferramenta que leva o professor a conhecer seu aluno, identificando o seu nível de desenvolvimento e de aprendizagem e as suas dificuldades e habilidades.

\section{Construtivismo e escola nova no Brasil}

A teoria construtivista chegou ao Brasil depois da primeira Guerra Mundial, no momento em que o Brasil estava no desenvolvimento das indústrias, de modo mais intenso na década de 80 , esta teoria era e ainda é objeto de estudo de muitos pesquisadores.

Baptista (2012, p. 34) ressalta que "as ideias advindas dos Estados Unidos e da Europa são apropriadas e reunidas sob o título de Escola Nova. Os professores que foram estudar nos Estados Unidos da América trazem para o ideário educacional brasileiro a educação progressiva ou escola ativa em Dewey". Por outro lado, os que "vão estudar na Europa trazem as ideias de Piaget e sua teoria construtivista é apropriada como o alicerce psicológico de sustentação da Escola Nova".

Nessa perspectiva, a influência dos estudos de John Dewey e Jean Piaget no movimento da Escola Nova favoreceu a consolidação de uma nova concepção de educação. Dewey destacava em seus estudos, que a educação não deve ser pautada apenas no resultado final da aprendizagem, mas sim deve levar em consideração todo o processo construção de conhecimento, independente se o sujeito tenha obtido "êxito" ou não.

Piaget destacava a aprendizagem como processo de adaptação ao meio esse ocorre com base na experiência, foi por meio de experimentos que o pesquisador chegou à definição que a 
inteligência é definida enquanto função e estrutura. Na perspectiva da função, a inteligência compreendida como um processo de adaptação do sujeito ao meio, no mesmo tempo em que ocorre o processo de adaptação ambos sofrem modificações, tanto o sujeito quanto o meio. E estrutural porque busca a organização dos processos. Contudo, o crescimento da inteligência se da no processo de reorganização da própria inteligência, esse processo perpassa a assimilação, acomodação e equilibração, sendo o conhecimento construindo com base no processo de experimentação. Pode-se dizer que a palavra construtivismo foi evidenciada por Piaget, sua origem vem da palavra construção que sua epistemologia é construtivista.

Por sua vez, Dewey apontava que os homens se desenvolvem socialmente em relação com outros homens e com o meio, ainda destacava a relevância de uma sociedade democrática, assim como da experiência na educação, sendo essa com um fim educativo, importante destacar que nem toda experiência é educativa. E ainda a experiência perpassar todo o processo educativo, sendo essa condição indispensável para a educação, esse processo acontece em todo o percurso da vida do sujeito.

Nesse contexto, a teoria construtivista traz para a educação um novo olhar, o aluno agora é protagonista de seu conhecimento, na vertente da teoria construtivista, os conhecimentos prévios dos sujeitos são levados em consideração, são esses que servirá de base para conhecimentos futuros. Esses conhecimentos prévios são adquiridos no meio social e cultural e resultam em uma "bagagem de conhecimento", os quais devem ser levados em consideração no processo educativo formal.

Contudo, essas transformações aconteceram na educação brasileira no final do século XXI e no início do século XX, esses avanços geraram novas necessidades para o sujeito em formação, esse teria que se adequar as necessidades do mercado industrial que estava em processo de constantes mudanças. Com isso a educação nova, ganhou mais em pulso, uma vez que sua principal característica era fazer o sujeito "aprender a aprender", como dito anteriormente o sujeito vai construir seu conhecimento, aprendendo a se relacionar e compreendendo os outros como sujeitos capazes de transformar a si e o meio.

Em uma outra perspectiva, Saviani (2008, p. 12) também destaca a importância do outro na construção do humano, ou seja, destaca que na educação o sujeito se constrói na relação com outros sujeitos. Ou seja, é por meio da interação como outros sujeitos e objetos que nos autoconhecemos e conhecemos o outro e o mundo humano, sendo essa condição necessária para a vida em sociedade. 
O movimento da Escola Nova no Brasil ocasionou grandes inovações para o ensino, provocando uma nova concepção de educação, sendo essa centrada no desenvolvimento do aluno, em uma formação do sujeito completo e com pensamentos críticos e reflexivos de tudo a sua volta. Isso ocorrerá devido, autonomia que é dada ao aluno, que possibilita construir seu conhecimento partindo de concepções já existentes. Com isso, o professor deixa de ser o centro do processo de aprendizagem, passando o aluno a ter um papel ativo no processo de construção de conhecimento, cabendo ao professor criar e organizar ambientes favoráveis para momentos de aprendizagens.

\section{Construtivismo e legislação oficial: uma breve análise}

A influência desta nova perspectiva para o ensino foi aos poucos tornando referencial teórico na elaboração de documentos oficiais de Educação. Hoje podemos identificar elementos da Teoria Construtivista nesses documentos. Nesse sentido, foi realizado um breve estudo em alguns documentos, na atualidade, que regem a educação, mais especificamente a primeira fase do Ensino Fundamenta (EF I), tais como: a Lei de Diretrizes e Bases da Educação Nacional (LDB), os documentos das Conferências Nacionais de Educação (CONAE) e o Plano Nacional de Educação (PNE) de 2014-2024.

A Lei de Diretrizes e Bases da Educação Nacional (LDB), Lei no 9.394/96, de dezembro de 1996, ressalta que o EF versa sobre como aprendemos, a influência de nosso ambiente natural e social e a estruturação de seu conhecimento, a exemplo do Art. 32 em que a formação básica do cidadão dar-se-á mediante: "o desenvolvimento da capacidade de aprender, tendo como meios básicos o pleno domínio da leitura, da escrita e do cálculo"; “compreensão do ambiente natural e social, do sistema político, da tecnologia, das artes e dos valores em que se fundamenta a sociedade", assim como "o desenvolvimento da capacidade de aprendizagem, tendo em vista a aquisição de conhecimentos e habilidades e a formação de atitudes e valores".

Esse aspecto fica ainda mais evidente no estudo sobre o documento final da Conferência Nacional de Educação de 2010 (CONAE, 2010³). O CONAE é um documento de âmbito nacional, que orienta o docente a conhecer o meio em que sua instituição e seu aluno se

${ }^{3} \mathrm{O}$ documento inicial da CONAE é fruto das "Conferências Municipais ou Intermunicipais [...] Estaduais e do Distrito Federal”, com “a participação de amplos segmentos educacionais e sociais”, que serviu de base para a Conferência Nacional de Educação (CONAE). Em abril de 2010, foi aprovado o Documento Final da Conferência Nacional de Educação (CONAE). Em 2014, é aprovado um novo documento da CONAE. 
encontram, pois este irá ter grande influência no processo de ensino e aprendizagem. $\mathrm{O}$ documento ressalta que a instituição educacional é um espaço de construção do conhecimento que deve ser levado em consideração o contexto sociocultural do meio em que a Escola esta inserida e a do sujeito. O documento salienta ainda a "construção de uma educação de qualidade deve considerar a dimensão socioeconômica e cultural, uma vez que o ato educativo se dá em um contexto de posições e disposições no espaço social” (BRASIL, 2010, p. 47).

Entretanto, o Documento aprovado na segunda Conferência da CONAE, em 2014, destaca que uma educação de qualidade deve estar voltada para a perspectiva de transformação da realidade, na busca por uma construção plena da cidadania e da garantia aos direitos humanos. Portanto é "a partir da concepção de mundo, ser humano, sociedade e educação que a escola procura desenvolver conhecimentos, habilidades e atitudes para encaminhar a forma pela qual o indivíduo vai se relacionar com a sociedade, com a natureza e consigo mesmo". Nesse sentido, uma "educação de qualidade" deve contribuir "com a formação dos estudantes nos aspectos humanos, sociais, culturais, filosóficos, científicos, históricos, antropológicos, afetivos, econômicos, ambientais e políticos, para o desempenho de seu papel de cidadão no mundo", enfim que a torna "uma qualidade referenciada no social” (BRASIL, 2014, p. 64).

Dessa forma, a Educação de Qualidade, segundo o documento, ocorre por meio de um processo de construção no qual, deve ser levado em consideração o sujeito completo, em seu meio sócio-histórico.

Numa educação emancipadora, o sentido de "qualidade" é decorrente do desenvolvimento das relações sociais (políticas, econômicas, históricas, culturais) e de sustentabilidade. Na atualidade tal compreensão requer que os processos educacionais, de crianças, jovens e adultos contribuam para a apropriação das condições de produção cultural e de conhecimentos e sua gestão para o fortalecimento da educação pública e privada, construindo uma relação efetivamente democrática (BRASIL, 2014, p. 64).

Com isso, vale ressaltar que a segunda CONAE traz uma proposta transformadora de educação, situando o sujeito como produtor de conhecimento e a educação como espaço de apropriação da cultura humanamente construída. Os documentos derivados das CONAE deveriam servir como orientação à construção dos Planos Nacionais de Educação (PNE).

Entretanto, o Plano Nacional de Educação (PNE) 2014-2024 reduz essa apropriação à articulação da educação com o meio social, apresentando 20 metas, através das quais se propõe a oferecer a todos uma educação de qualidade, destacando que a "oferta de educação básica de qualidade para todos, apresenta-se, como um complexo de grandes desafios para as políticas 
públicas e para o conjunto dos agentes que atuam no campo da educação, sobretudo nas escolas públicas".

Além desse aspecto, o texto aponta que a educação deve propor uma articulação entre escola e sociedade, no que refere a uma "melhor definição e articulação entre os sistemas de ensino e unidades escolares, processos de organização e gestão do trabalho escolar, melhoria das condições de trabalho e valorização, formação e desenvolvimento profissional de todos aqueles que atuam na educação", destacando o papel fundamental da definição e implementações de dinâmicas curriculares que favoreçam aprendizagens significativas aos alunos em articulação com o meio sociocultural dos alunos.

\section{Considerações finais}

Ao longo deste trabalho buscou-se compreender a difusão da teoria construtiva no Brasil, identificando possíveis elementos desta teoria nos documentos oficiais de educação. A partir dos estudos realizados, vale destacar que a educação brasileira encontra-se em processo de mudanças, desde que, na segunda metade do Século XX, as ideias de Piaget assim como as de Dewey embasaram a denominada Escola Nova no Brasil.

$\mathrm{Na}$ análise dos documentos que regem a EF I, LDB, CONAE e PNE pode ser constatado que a teoria construtivista não é apresentada de forma explícita, mas, nas entrelinhas dos textos das Leis, apesar da CONAE 2014 trazer, mais explicitamente, uma concepção mais emancipadora da educação na perspectiva de uma apropriação do conhecimento historicamente produzido e que deve ser apropriado pela nova geração através da educação.

Com os resultados obtidos, surgiram novos questionamentos acerca da temática no âmbito da nova realidade educacional, o que nos impõe a necessidade de uma discussão mais ampla e detalhada. Espera-se, que esse introdutório estudo possa servir de parâmetro para aqueles que desejam conhecer e refletir em uma perspectiva construtivista, uma vez que a escola é um todo e não deve ser compreendida de modo fragmentado.

\section{REFERÊNCIAS}

AZENHA, M. G. Construtivismo: de Piaget a Emilia Ferreiro. São Paulo: Ática, 1999. 
BAPTISTA, M. G. A. Gramsci e Vigotski: da educação ativa à educação crítica. João Pessoa: Editora da UFPB, João Pessoa, 2012.

BECKER, F. Educação e Construção do Conhecimento. Porto Alegre: Artmed, 2001.

BRASIL. Documento Final da Conferência Nacional de Educação - CONAE. Disponível em: http://fne.mec.gov.br/images/doc/DocumentoFina240415.pdf. Acesso em: 21 jul. 2018.

BRASIL. Lei 9.394, de 1996. Lei de Diretrizes e Bases da Educação Nacional. Brasília, Senado Federal, 1996.

BRASIL. Plano Nacional de Educação - 2014-2024. Disponível em: http://pne.mec.gov.br/images/pdf/pne_conhecendo_20_metas.pdf. Acesso em: 28 de abril de 2018.

DEWEY, J. Democracia e educação. São Paulo: Nacional, 1959.

MIZUKAMI, M. G. N. Ensino: as abordagens do processo. São Paulo: EPU, 1986.

PIAGET, J. Biologia e conhecimento. Petrópolis: Vozes, 1973.

PIAGET, J. Para onde vai a educação? Rio de Janeiro: Livraria José Olympio Editora, 1975.

ROSA, S. Construtivismo e mudanças. 10. ed. São Paulo: Cortez, 2007.

SAVIANI. D. A pedagogia no Brasil: história e teoria. Campinas, SP: Autores Associados, 2008.

\section{Como referenciar este artigo}

ANDRADE; Maria Aparecida Rosa; BAPTISTA, Maria das Graças de Almeida. Documentos oficiais de educação no Brasil e a teoria construtivista piagetiana. Revista on line de Política e Gestão Educacional, Araraquara, v. 23, n. 2, p. 255-265, maio/ago., 2019. E-ISSN:15199029. DOI: 10.22633/rpge.v23i2.11695

Submetido em: 14/08/2018

Revisões requeridas: 13/10/2018

Aprovado em: 26/12/2018

Publicado em: 06/03/2019 